\title{
Quantitative real-time RT-PCR and chromogenic in situ hybridization: precise methods to detect HER-2 status in breast
} carcinoma

\author{
Fabíola E Rosa ${ }^{1}$, Sara M Silveira ${ }^{1}$, Cássia GT Silveira ${ }^{1}$, Nádia A Bérgamo ${ }^{2,7}$, \\ Francisco A Moraes Neto ${ }^{3}$, Maria AC Domingues ${ }^{4}$, Fernando A Soares ${ }^{5}$, \\ José RF Caldeira ${ }^{6}$ and Silvia R Rogatto*2,7
}

Address: ${ }^{1}$ Department of Genetics, Institute of Biosciences, UNESP - São Paulo State University, Botucatu, Sao Paulo, Brazil, ${ }^{2}$ Department of Urology, Faculty of Medicine, UNESP - São Paulo State University, Botucatu, Brazil, ${ }^{3}$ Department of Pathology, Amaral Carvalho Hospital, Jaú, São Paulo, Brazil, ${ }^{4}$ Department of Pathology, Faculty of Medicine, UNESP - São Paulo State University, Botucatu, São Paulo, Brazil, ${ }^{5}$ Department of Pathology, Fundação Antonio Prudente, Hospital AC Camargo, São Paulo, Brazil, 'Department of Senology, Amaral Carvalho Hospital, Jaú, São Paulo, Brazil and ${ }^{7}$ NeoGene Laboratory, Fundação Antonio Prudente 211, Hospital AC Camargo - Liberdade São Paulo, Brazil

Email: Fabíola E Rosa - fabiolarosa7@yahoo.com.br; Sara M Silveira - sara_martorelli@yahoo.com.br;

Cássia GT Silveira - terrassani@fmb.unesp.br; Nádia A Bérgamo - nbergamo@yahoo.com.br; Francisco A Moraes Neto - fr.jau@uol.com.br; Maria AC Domingues - mdomingues@fmb.unesp.br; Fernando A Soares - fernandosoares@hcancer.org.br; José RF Caldeira - caldeira@netsite.com.br; Silvia R Rogatto* - rogatto@fmb.unesp.br

* Corresponding author

Published: 23 March 2009

BMC Cancer 2009, 9:90 doi:10.1 |86/147|-2407-9-90
Received: II June 2008

Accepted: 23 March 2009

This article is available from: http://www.biomedcentral.com/I47I-2407/9/90

(c) 2009 Rosa et al; licensee BioMed Central Ltd.

This is an Open Access article distributed under the terms of the Creative Commons Attribution License (http://creativecommons.org/licenses/by/2.0), which permits unrestricted use, distribution, and reproduction in any medium, provided the original work is properly cited.

\begin{abstract}
Background: HER-2 gene testing has become an integral part of breast cancer patient diagnosis. The most commonly used assay in the clinical setting for evaluating HER-2 status is immunohistochemistry (IHC) and fluorescence in situ hybridization (FISH). These procedures permit correlation between HER-2 expression and morphological features. However, FISH signals are labile and fade over time, making post-revision of the tumor difficult. CISH (chromogenic in situ hybridization) is an alternative procedure, with certain advantages, although still limited as a diagnostic tool in breast carcinomas.
\end{abstract}

Methods: To elucidate the molecular profile of HER-2 status, mRNA and protein expression in 75 invasive breast carcinomas were analyzed by real time quantitative RT-PCR (qRT-PCR) and IHC, respectively. Amplifications were evaluated in 43 of these cases by CISH and in II by FISH.

Results: The concordance rate between IHC and qRT-PCR results was $78.9 \%$, and $94.6 \%$ for $\mathrm{qRT}-\mathrm{PCR}$ and $\mathrm{CISH}$. Intratumoral heterogeneity of HER-2 status was identified in three cases by $\mathrm{CISH}$. The results of the three procedures were compared and showed a concordance rate of 83.8\%; higher discordances were observed in 0 or I+ immunostaining cases, which showed high-level amplification (15.4\%) and HER-2 transcript overexpression (20\%). Moreover, 2+ immunostaining cases presented nonamplified status (50\%) by CISH and HER-2 downexpression (38.5\%) by qRT-PCR. In general, concordance occurred between $\mathrm{QRT}-\mathrm{PCR}$ and $\mathrm{CISH}$ results. A high concordance was observed between CISH/ qRT-PCR and FISH. Comparisons with clinicopathological data revealed a significant association between HER-2 downexpression and the involvement of less than four lymph nodes $(P=0.0350)$.

Conclusion: Based on these findings, qRT-PCR was more precise and reproducible than IHC. Furthermore, CISH was revealed as an alternative and useful procedure for investigating amplifications involving the HER-2 gene. 


\section{Background}

In breast cancer, the assays routinely used in clinical practice are those that address a specific management decision. Hormonal therapy is based on estrogen receptor (ESR) and progesterone receptor (PGR) status. Trastuzumab (Herceptin ${ }^{\mathrm{TM}}$, Genentech, Inc, San Francisco, CA, USA) therapy, a humanized monoclonal antibody, is based on HER-2 status.

ERBB2/HER-2 (HER-2/neu, NEU, NGL, HER2, TKR1, CD340) encodes a membrane receptor protein in the growth factor receptor gene family presenting tyrosine kinase activity $[1,2]$. HER-2 plays a role in the pathogenesis of a significant number of human tumors. It is altered in approximately $20-30 \%$ of breast carcinomas and this is manifested as gene amplification and/or protein overexpression [3-5]. These alterations are associated with a shorter disease free period and overall survival and with resistance to tamoxifen antiestrogen therapy and other chemotherapy regimens, regardless of the nodal or hormone receptor status $[3,4,6,7]$. Moreover, breast carcinoma patients presenting HER-2 amplification or overexpression can benefit from anthracycline-based regimens, as well as trastuzumab [8].

The therapy choice for breast cancer patients depends on the discrimination of HER-2 status. Reliable laboratory data in evaluating HER-2 status is essential, because the treatment is beneficial for advanced breast cancer and avoids potential cardiotoxic effects in women not showing amplification and overexpression [9]. The most commonly used assay in the clinical setting for evaluating HER-2 status is immunohistochemistry (IHC) and fluorescence in situ hybridization (FISH), both approved by the FDA (U.S. Food and Drug Administration). More recently, the CISH (chromogenic in situ hybridization) methodology, also approved by FDA, has emerged as a potential alternative to FISH. When compared with FISH, CISH has been described as having several advantages. CISH does not require an expensive fluorescence microscope with multi-band-pass filters, it produces a permanent staining and samples can be archived indefinitely, thus avoiding archival recording with an expensive CDD camera. The morphology is easier to analyze, particularly for distinguishing invasive cancer cells and in situ components. Moreover, tumor heterogeneity is promptly identified, even at low magnification $(20 \times)$ [10-13]. In FISH analysis, tissue morphology and gene amplification are primarily disconnected because of tumor cells for signal evaluation are based on nuclear DAPI (4', 6-Diamidino-2phenylindole) or propidium iodide staining, which does not always permit adequate histopathological evaluation of the cells [14]. CISH is a useful methodology for confirming ambiguous IHC results [11]. In addition, polymerase chain reaction (PCR) based technology has been demonstrated to successfully evaluate specific mRNAs, especially those present in low copy numbers in a small number of cells or in small quantities of tissue, and mRNAs expressed in mixed-cell populations. Quantitative real time reverse transcript PCR (qRT-PCR) is a quantitative method easily amenable to standardization. However, qRT-PCR suffers from the same drawback as other PCR-based methods. The tumor cell population within the tissue under evaluation must be isolated, the template quality, operator variability, subjectivity in data analysis and reporting are technical aspects that must be considered $[14,15]$. This procedure is an alternative for scoring HER-2 status in human breast cancer. Limitations based on tumor heterogeneity and amplification of HER2 in noninvasive cancer can be eliminated by the use of laser microdissection, although this seems to be impracticable for routine diagnosis [14].

The purpose of the current study was to assess agreement between gene amplification detection by CISH and transcript (qRT-PCR) and protein (IHC) expression, as well as to evaluate their relevance for determining HER-2 status in breast carcinomas. In addition, the data were correlated with clinicopathological features, such as tumor size, lymph node status, histological grade and Ki-67 status.

\section{Methods \\ Patients}

Seventy-five breast carcinoma samples were obtained between 2000 and 2004, from Amaral Carvalho Hospital, Jaú (SP, Brazil). The patients were accrued consecutively and the criterion for inclusion in the study was no previous histological diagnosis of breast cancer. Patients underwent segmental resection or mastectomy and none of them had received radiotherapy or chemotherapy prior to surgery. All patients were advised of the procedures and provided written informed consent. The Ethics Committee from Amaral Carvalho Hospital Foundation approved this study (CEPFHAC 007/05).

Seventy tumors were infiltrating ductal and five infiltrating lobular carcinomas, in which most presented operable stage II and III breast cancer and positive axillary lymph nodes. Most patients were more than 50 years-old (64\%) with a mean of $58 \pm 15.5$ years (range, 30-94 years); most tumors were more than $2 \mathrm{~cm}(73.3 \%)$ and half of them showed low Ki-67 positivity. The mean follow-up was $49.8 \pm 20.1$ months (varying between 23 to 83 months) During this interval, five patients died due to unrelated causes, two patients presented recurrence in the same breast, eight presented metastasis (two spreading to the bone and six to the lung) and six missed their follow-ups. Patients with a family history of cancer were noted, particularly among first-degree and second-degree relatives, and whenever possible, the cancer was confirmed with docu- 
mented medical records or ascertained from the death certificate (Table 1). The patients received different chemotherapy treatments: AC (adriamycin, cyclophosphamide); FEC (5-fluorouracil, 4-epirubicin, cyclophosphamide); FAC (5-fluorouracil, adriamycin, cyclophosphamide); CMF (cyclophosphamide, methotrexate, 5-fluorouracil), at $100 \%$ or $70 \%$ of the dose, according to the age and clinical status of the patient. Fifty-five patients $(73 \%)$ received radiotherapy and 51 ESR1 positive and/or PGR positive cases (68\%), as determined by IHC analysis, were treated with tamoxifen (20 $\mathrm{mg} /$ day) for 60 months at the end of the chemotherapy treatment. Some patients presenting intolerance or side effects (postmenopausal) were treated with aromatase inhibitors, such as anastrozole $(1 \mathrm{mg} /$ day) or letrozole $(2.5 \mathrm{mg} /$ day $)$.

Histopathological classification was performed according to the WHO International Classification of Disease for
Oncology [16] and clinical stage was determined according to the UICC TNM classification [17]. The malignancy of infiltrating carcinomas was scored according to the Scarff-Bloom and Richardson grading system [18].

\section{HER-2 copy number alterations}

In 43 out of 75 samples that presented available histological sections, CISH analysis was performed (32 additional cases are part of the Hospital's sample bank especially devoted to diagnosis). Eleven cases that presented adequate tumor samples on slides were evaluated by dual color FISH. CISH and FISH were carried out on $4 \mu \mathrm{m}$ thick archival formalin fixed paraffin embedded tumour samples using a Zymed SPoT-Light HER2 CISH Kit (Zymed Laboratories Inc, San Francisco, CA) and a HER2 FISH pharmDx ${ }^{\mathrm{TM}}$ Kit (DakoCytomation, Denmark), respectively, according to manufacturers' instructions. At least 200 non-overlapping tumor cell nuclei were evaluated by CISH. According to the manufacturer's instructions, the

Table I: Comparison of clinicopathological features with HER-2 status using CISH, qRT-PCR (qPCR), and IHC.

\begin{tabular}{|c|c|c|c|c|c|c|c|c|c|}
\hline \multirow[t]{2}{*}{ Variables $(n)^{a}$} & \multicolumn{2}{|c|}{ CISH } & \multirow[t]{2}{*}{$P *$} & \multicolumn{2}{|c|}{ qPCR } & \multirow[t]{2}{*}{$\mathbf{P} *$} & \multicolumn{2}{|c|}{ IHC } & \multirow[t]{2}{*}{$P *$} \\
\hline & $\leq \mathbf{5}$ & $>10$ & & $\leq \mathbf{2 . 0 0}$ & $>2.00$ & & $0 / 1+$ & $2 / 3+$ & \\
\hline \multicolumn{10}{|l|}{ Age (years) } \\
\hline$\leq 50$ & 9 & 5 & 0.9541 & 15 & 13 & 0.2569 & 17 & 11 & $0.365 I$ \\
\hline$>50(48)$ & 15 & 8 & & 32 & 16 & & 34 & 14 & \\
\hline \multicolumn{10}{|c|}{ Lymph node status } \\
\hline$<4(57)$ & 21 & 9 & 0.1756 & 38 & 19 & 0.0915 & 40 & 17 & 0.4723 \\
\hline$\geq 4(32)$ & 3 & 4 & & 8 & 10 & & 11 & 7 & \\
\hline ND (I) & 0 & 0 & & 0 & 1 & & 0 & 1 & \\
\hline \multicolumn{10}{|l|}{ Tumor Size (cm) } \\
\hline $0-2(19)$ & 5 & 5 & 0.1883 & 10 & 9 & 0.2953 & 11 & 8 & 0.2745 \\
\hline$>2(56)$ & 19 & 7 & & 37 & 19 & & 40 & 16 & \\
\hline ND (I) & 0 & 1 & & 0 & 1 & & 0 & 1 & \\
\hline \multicolumn{10}{|l|}{ Clinical Stage } \\
\hline I/IIA/IIB (65) & 21 & 9 & 0.1756 & $4 I$ & 24 & 0.5901 & 44 & 21 & 0.7912 \\
\hline IIIA/IIIB (II) & 3 & 4 & & 6 & 5 & & 7 & 4 & \\
\hline \multicolumn{10}{|l|}{ Histologic grade } \\
\hline $\mathrm{I} / \mathrm{II}(36)$ & 10 & 6 & 1.000 & 22 & 14 & 0.9237 & 23 & 13 & 0.6767 \\
\hline III (35) & 10 & 6 & & 21 & 14 & & 24 & 11 & \\
\hline ND (5) & 4 & 1 & & 4 & 1 & & 4 & 1 & \\
\hline \multicolumn{10}{|l|}{ Ki-67 status } \\
\hline Low $(\leq 25 \%)(32)$ & 11 & 6 & 0.5133 & 19 & 13 & 0.5354 & 21 & 11 & 0.7209 \\
\hline High $(>25 \%)(3 I)$ & 8 & 7 & & 16 & 15 & & 19 & 12 & \\
\hline Not reactive (13) & 5 & 0 & & 12 & 1 & & 11 & 2 & \\
\hline \multicolumn{10}{|c|}{ Familial History of Cancer } \\
\hline Yes (I5) & 4 & 3 & 0.6346 & 7 & 8 & 0.1769 & 10 & 5 & 0.9678 \\
\hline No $(6 \mathrm{I})$ & 20 & 10 & & 40 & 21 & & 41 & 20 & \\
\hline
\end{tabular}

a Number of the cases evaluated by qRT-PCR and IHC, while 37 cases were evaluated using CISH.

* Chi-Square test.

ND: not determined. 
tumors were classified depending on the number of HER2 gene copies in the nuclei as: (a) nonamplified, those tumor cells with two to five brown intranuclear spots per nucleus; (b) low-level amplification, when six to 10 signals per nucleus were detected in more than $50 \%$ of tumor cells or when a small coalescing signal cluster was found; (c) high-level amplification, defined as more than 10 copies per nucleus or when copy clusters were observed in more than $50 \%$ of cancer cells.

By FISH, HER-2 and chromosome 17 centromere signals were counted in at least 60 nuclei; a HER-2/CEP-17 ratio $\geq 2.0$ was considered positive for HER-2 gene amplification [19]. A fluorescence microscope (Olympus AX61, Olympus Optical, Hamburg, Germany), equipped with a CCD camera (Photometrics CH 250, Huntington Beach, $\mathrm{CA})$ was used. Image analysis was performed with the software Applied Spectral Imaging CGH View 3.0 (Olympus).

Slides from both procedures were randomly distributed to three independent blinded observers (SMS, CGTS, and $\mathrm{NAB}$ ). Any discrepancy in sample classification was addressed by immediate review and the final result was reached by consensus. In addition, different individually identified tumor areas were analyzed.

\section{Isolation of tumoral cells by microdissection}

Immediately after surgery, the tumor samples were frozen at $-80^{\circ} \mathrm{C}$. Eight successive unstained slides from frozen samples were prepared using a cryostat and stored at $80^{\circ} \mathrm{C}$. The first and the last slides were stained with hematoxylin-eosin for histopathological evaluation. Tumoral components were precisely outlined and labeled under the microscope. The defined areas were retrieved by manual microdissection. To minimize dilution of the PCR signal by nontumoral and nonamplified cells, sections containing at least $90 \%$ tumor cells were selected for RNA extraction.

\section{Total RNA isolation and reverse transcription}

Total RNA was extracted from pulverized frozen tumor tissue using the Rneasy mini Kit (Qiagen GmbH, Hilden, Germany), according to the manufacturer's instructions. Reverse transcription using SuperScript ${ }^{\mathrm{TM}}$ II reverse transcriptase (Invitrogen Life Technologies Inc., Carlsbad, CA) was carried out for $60 \mathrm{~min}$ at $42^{\circ} \mathrm{C}$ and the reaction mixture was subsequently inactivated for $15 \mathrm{~min}$ at $70^{\circ} \mathrm{C}$ as previously described [20]. The cDNA was stored at $-70^{\circ} \mathrm{C}$.

\section{Real time quantitative RT-PCR (qRT-PCR)}

Seventy-five breast carcinomas were evaluated by qRTPCR. Four normal breast tissue samples from patients who underwent mammary reduction and confirmed as histopathologically normal were used as controls. PCR amplification was performed in an ABI Prism 7000
Sequence Detection System (Applied Biosystems, Foster City, CA, USA). Primers and TaqMan probes for HER-2 and the GAPDH control reference gene were designed and synthesized according to Taqman Gene Expression Assay (assays Hs00170433_m1 and 4326317E, respectively) (Applied Biosystems, Foster City, CA, USA). Quantitative data was analyzed using the Sequence Detection System software (v1.0; Applied Biosystems). PCR reactions were carried out in a total volume of $10 \mu \mathrm{L}$, according the manufacturer's instructions. A relative standard curve was constructed for all primers with serial dilutions of placenta cDNA $(100,50,25,12.5$, and $8 \mathrm{ng} / \mathrm{uL})$. The standard curves of the target and reference genes showed similar results of efficacy (>90\%). The reactions were performed in duplicate. The relative quantification (RQ) was given by the ratio between the mean value of the target gene and the mean value of the reference gene (GAPDH) in each sample. The relative amount of PCR product generated from each primer set was determined on the basis of the cycle threshold $(\mathrm{Ct})$ value. The RQ was calculated by $2^{-}$ $\triangle \triangle \mathrm{CT}$ [21]. HER-2 relative expression level was compared with the ratio of healthy controls. Overexpression was defined as the mean HER-2/reference gene ratio RQ>2.00.

\section{Immunohistochemistry (IHC)}

HER-2 protein levels were performed using rabbit monoclonal antibody (SP3 Clone) (Thermo Fisher Scientific, Fremont, CA, USA) (dilution 1:100) in 75 cases. After incubation for one hour, the sections were washed in PBS, incubated for $30 \mathrm{~min}$ with secondary biotinylated antibody and treated for $30 \mathrm{~min}$ with streptavidin peroxidase complex (LSAB, DAKO, Carpinteria, CA, USA). The sections were developed with 3,3'-diaminobenzidine (DAB) and counterstained with hematoxylin. Negative and positive control slides were included in each assay. The results were scored as: (0) no immunoreactivity; $(1+)$ weak and incomplete immunoreactivity; $(2+)$ weak and complete membrane immunoreactivity in more than $10 \%$ of the tumor cells or strong and complete membrane immunoreactivity in less than $10 \%$ of the tumor cells; and (3+) strong and complete membrane immunoreactivity in more than $10 \%$ of the tumor cells. Slides were randomly distributed to two independent blinded observers (FAMN and MACD). Only the invasive component of the neoplasia was assessed and scored. The level of Ki- 67 was evaluated in all cases, but 13 cases were nonreactive. Ki-67, ESR1, and PGR protein expression was performed as described by Rosa et al. [20].

\section{Statistical Analysis}

Comparisons between HER-2 expression (qRT-PCR and IHC), gene copy number (CISH) and several clinicopathological features were calculated using the Chi square test. Six patients that missed follow-up were censored as survivors in the statistical calculations. The correlation between the three methodologies was evaluated using 
One-way Analysis of Variance (ANOVA); differences were tested for significance by the Mann-Whitney test for two categories and by the Kruskal-Wallis test for three categories. Statistical significance was designated at $P<0.05$. The concordance rate was obtained considering: (a) amplification by CISH and transcript overexpression $(\mathrm{RQ}>2.00)$ and 2+ or 3+ immunostaining; (b) nonamplification by $\mathrm{CISH}$ and transcript downexpression $(\mathrm{RQ} \leq 2.00)$ and 0 or $1+$ immunostaining.

\section{Results}

Breast cancer samples were assessed by HER-2 gene amplification and protein expression in histological samples using CISH and IHC, respectively (Figure 1). Transcript expression was evaluated by qRT-PCR in fresh samples after microdissection. HER-2 data obtained in all the procedures are shown in Tables 2 and 3.

CISH was performed on 43 cytological samples; in three of these cases the spots presented inconclusive results; the brown spots were undistinguished. Twenty-four out of 37 tumors $(64.9 \%)$ were not amplified by CISH, while 13 samples (35.1\%) showed high-level HER-2 amplification. Different areas of the tumor were evaluated and the final analysis showed agreement, except in three cases (Figure $2 \mathrm{~A}-\mathrm{C}$ ). Case A presented an equivalent number of nonamplified cells (2 copies and 3-5 copies) in area 1 and more than $50 \%$ of the cells with high-level amplification in area 2 (this case presented 0 score by IHC and normal expression level by qRT-PCR). Case B showed nonamplified cells in both areas, but in area 2, low-level and highlevel amplification cells were also observed (IHC, 0 score; qRT-PCR, overexpression). Case C showed preferentially nonamplified cells; however, in area 1, cells with 3-5 copies were predominant and in area 2, a prevalence of two HER-2 copies was detected and the presence of sporadic cells with high-level amplification was also found (IHC, $3+$ score; qRT-PCR, overexpression). More than 400 cells were evaluated for each of these cases. In the other samples (37 cases), the nuclear features were maintained, the morphological details were apparent and large gene copy clusters were easily detected at low magnification. Normal epithelial cells and lymphocytes showed one or two HER2 signals per nucleus.

HER-2 amplification status by FISH was evaluated in 11 out of 43 cases investigated by CISH. The comparison between CISH and FISH revealed agreement in eight cases that presented high-level HER-2 amplification. These cases presented scores $2+$ (two cases) and $3+$ (six cases) by IHC. Only one of them, identified as amplified by CISH, showed sporadic cells $(<10 \%$ of the cells) with polyploidy. The three cases that presented heterogeneity in two different areas of the tumor by CISH were also evaluated by FISH (Figure 2A-C). Case A presented similar results to that observed in the area 1 detected by $\mathrm{CISH}$;
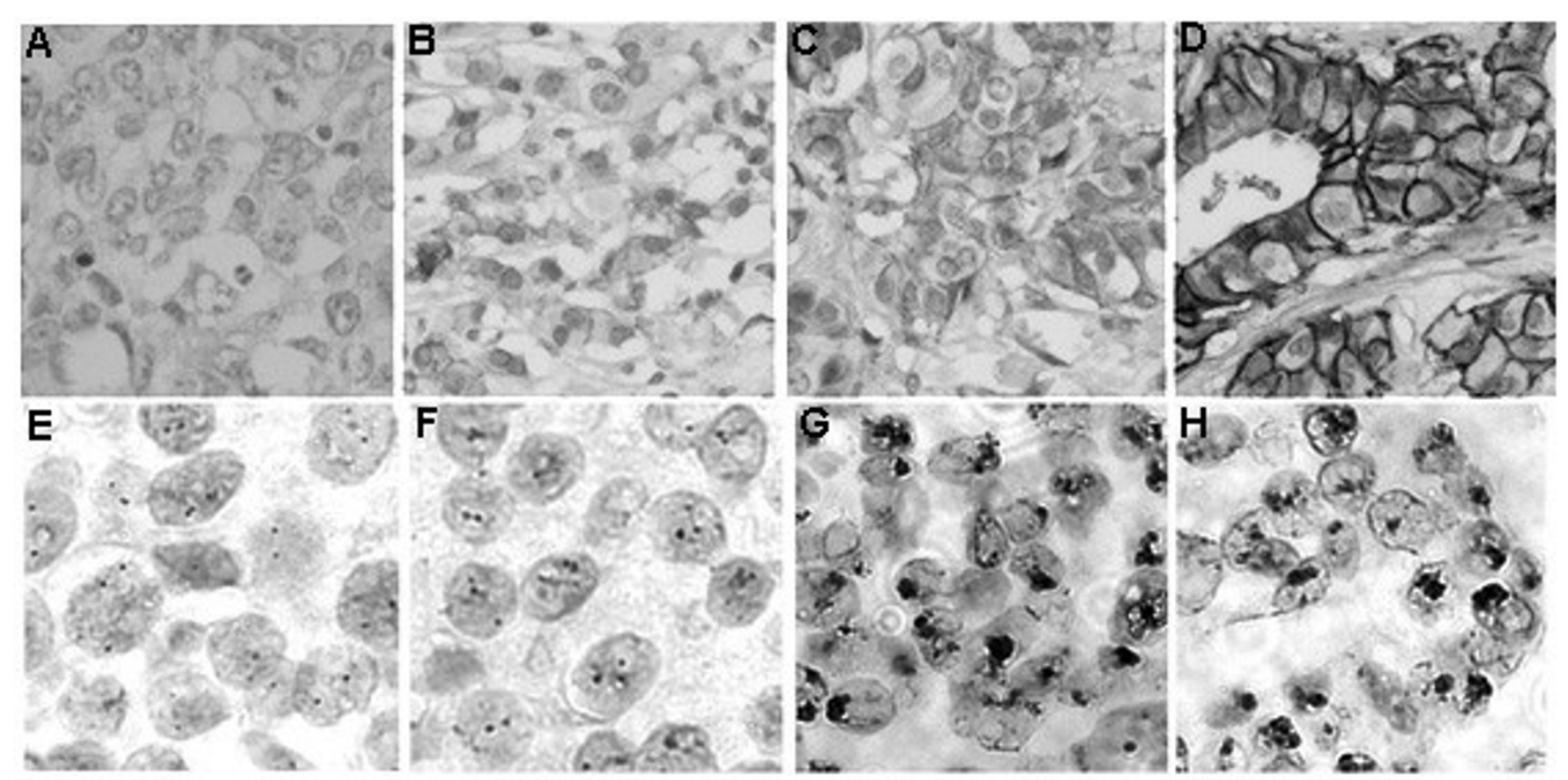

Figure I

Breast cancer cells showing immunohistochemistry and chromogen in situ hybridization results of HER-2. (A-D) IHC: HER-2 protein expression scored as $0(A), I+(B), 2+(C)$, and 3+ (D); (E-H) CISH: HER-2 gene detected in nuclei with two signals $(E)$, more than two signals $(F)$, and high-level amplification $(\mathrm{G}-\mathrm{H})$. 
Table 2: Comparison between protein expression by IHC and gene amplification by CISH and FISH.

\begin{tabular}{ccccc}
\hline & \multicolumn{2}{c}{ CISH (n= 37) } & FISH (n= 8) \\
\cline { 2 - 5 } IHC & No amplification (\%) & High amplification (\%) & No amplification (\%) & Amplification (\%) \\
\hline \multirow{2}{*}{$\begin{array}{c}\text { or I+ } \\
2+\end{array}$} & $22(84.6)$ & $4(15.4)$ & $0(0.0)$ & $0(0.0)$ \\
$3+$ & $2(50.0)$ & $2(50.0)$ & $0(0.0)$ & $2(25.0)$ \\
$6(75.0)$ & $0(0.0)$ & 0 \\
\hline Total & $0(0.0)$ & $7(100)$ & 0 & 8 \\
\hline
\end{tabular}

amplification was observed in only $10 \%$ of the cells. Cases $\mathrm{B}$ and $\mathrm{C}$ showed principally no amplification by FISH, comparable to that detected by CISH (case B: $90 \%$ of the tumoral cells were not amplified and 10\% presented polyploidy; case C: no amplification in $90 \%$ of the cells and amplification in 10\%). An overall concordance between $\mathrm{CISH}$ and FISH results was found.

HER-2 relative expression level was evaluated in 75 samples by qRT-PCR in comparison with four healthy breast tissue and ranged between $R Q=0.05$ to 20.43. Overexpression (RQ>2.00) was observed in 29 out of 75 cases $(38.7 \%)$.

Among the 75 cases analyzed by IHC, 50 (66.7\%) presented a score of 0 or $1+$. The $2+$ immunostaining cases comprised 13 samples (17.3\%) and 12 cases (16.0\%) presented $3+$ scoring.

\section{CISHIFISH compared to IHC analysis}

Four out of 26 cases (15.4\%) presenting 0 or $1+\mathrm{immu}$ nostaining scores showed high-level amplification by CISH. Two out of four samples (50\%) scored as $2+$ presented high-level amplification by CISH. All cases presenting 3+ scoring showed amplification by CISH (Table 2). The concordance rate between CISH and IHC was $83.8 \%$ (31 cases). Eight cases scored as $2+/ 3+$ evaluated by FISH showed amplification.

\section{qRT-PCR compared to IHC results}

HER-2 transcript levels were significantly lower in cases presenting low protein expression $(0$ or $1+)$ than in cases presenting high expression (3+) (Figure 3A). Ten out of 50 cases $(20 \%)$ presenting a score of 0 or $1+$ showed overexpression by qRT-PCR. Seven out of 12 samples (58.3\%) comprising 2+ immunostaining showed overexpression by qRT-PCR. Twelve out of 13 cases $(92.3 \%)$ which pre-

Table 3: Transcript expression by $q R T-P C R$ in relation to protein expression and gene amplification using IHC and CISH/FISH methodologies, respectively.

\begin{tabular}{|c|c|c|c|c|c|}
\hline & \multirow[b]{2}{*}{ n (\%) } & \multicolumn{4}{|c|}{ qRT-PCR } \\
\hline & & HER-2 ratio (range) * & $P$ & $\begin{array}{c}\text { Ratio } \\
\leq \mathbf{2 . 0 0} \\
\text { n (\%) }\end{array}$ & $\begin{array}{l}\text { Ratio } \\
>2.00 \\
\text { n (\%) }\end{array}$ \\
\hline \multicolumn{6}{|l|}{ IHC } \\
\hline 0 or $1+$ & $50(66.7)$ & $0.93(0.05-12.24)$ & $<0.000 \mathrm{I}^{\mathrm{a}}$ & $40(80.0)$ & $10(20.0)$ \\
\hline $2+$ & $12(17.3)$ & $2.46(1.15-7.61)$ & & $5(4 \mid .7)$ & $7(58.3)$ \\
\hline $3+$ & $13(16.0)$ & 7.55 (1.07-20.43) & & I (7.7) & $12(92.3)$ \\
\hline Total & 75 & & & & \\
\hline \multicolumn{6}{|l|}{ CISH } \\
\hline No amplification & $24(64.9)$ & $0.75(0.05-1.95)$ & $<0.000 \mathrm{Ib}^{\mathrm{b}}$ & $24(100)$ & $0(0.0)$ \\
\hline High amplification & $13(35.1)$ & $4.69(1.07-20.43)$ & & $2(I 5.4)$ & II (84.6) \\
\hline Total & 37 & & & & \\
\hline \multicolumn{6}{|l|}{ FISH } \\
\hline No amplification & $0(0.0)$ & $0(0.0)$ & ND & $0(0.0)$ & $0(0.0)$ \\
\hline Amplification & $8(100)$ & 7.93 (2.64-20.43) & & $0(0.0)$ & $8(100)$ \\
\hline Total & 8 & & & & \\
\hline
\end{tabular}

* Mean HER-2/reference gene ratios; ND: not determined.

a Kruskal-Wallis test.

b Mann-Whitney test. 


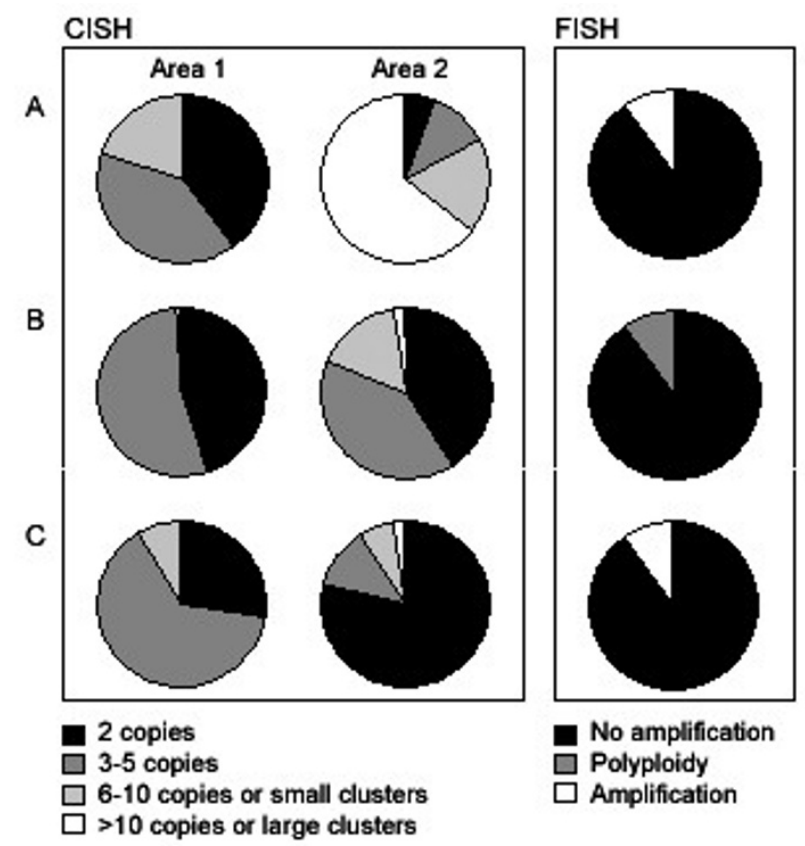

Figure 2

Intratumoral heterogeneity of HER-2 gene status detected by chromogen in situ hybridization in two different areas (areas $I$ and 2) from three breast tumors (A, B, and C). Nonamplified HER-2 gene (2-5 copies per nucleus), low-level amplification (6-10 copies or small clusters) and high-level amplification (>10 copies or large clusters) were observed in different areas from the same tumor. FISH results of the same cases are represented on the right side of the figure.

sented a score of $3+$ overexpressed HER-2 transcript (Table 3). Concordance between qRT-PCR and IHC was observed in 59 cases $(78.7 \%)$.

\section{qRT-PCR compared to CISHIFISH analysis}

Concordance between qRT-PCR and CISH was observed in 35 cases $(94.6 \%)$. HER-2 mRNA levels were significantly lower in nonamplified cases by CISH (Figure 3B). None of the 24 nonamplified cases by CISH showed HER2 overexpression. Eleven out of 13 cases (84.6\%) presented both, high-level amplification and HER-2 overexpression by qRT-PCR. All cases showed HER-2 overexpression and amplification by FISH (Table 3).

Among the 37 cases evaluated by all three methodologies (CISH, qRT-PCR, and IHC), 31 (83.8\%) showed concordance. Discrepancies were found in six cases; four cases 0 or $1+$ by IHC showed HER-2 gene overexpression and were amplified by CISH; and two cases $2+$ by IHC showed $H E R-2$ gene $\mathrm{RQ} \leq 2.00$ and were not amplified by $\mathrm{CISH}$ (Figure 3C).

\section{Clinico-pathological data in comparison with HER-2 status}

HER-2 data were also compared to clinicopathological features (Table 1). No statistical correlation was observed with age, tumor size, clinical stage, histological grade, Ki67 status or familial history of cancer. A marginally significant correlation with lymph node status was detected: $82.6 \%$ of the cases presenting RQ $\leq 2.00$ showed less than four positive lymph nodes $(P=0.0915)$. Comparison of individual HER-2 relative quantification values between the two classes of lymph node status $(<4$ and $\geq 4)$ showed a significant correlation $(P=0.0350)$, confirming the association between cases presenting $\mathrm{RQ} \leq 2.00$ and the involvement of less than four positive lymph nodes (Figure 4).

In the four lobular carcinomas evaluated by all three methodologies (CISH, qRT-PCR, and IHC), two presented discordant results: one case showed high-level amplification by CISH, HER-2 overexpression by qRT-PCR and negative immunostaining; the other sample presented nonamplified by CISH, RQ $\leq 2.00$ by qRT-PCR and $2+$ immunostaining by IHC analysis. The two remaining cases were nonamplified, $\mathrm{RQ} \leq 2.00$ and negative immunostaining. The case evaluated exclusively by qRT-PCR and IHC presented RQ $\leq 2.00$ and negative immunostaining. Individual values of HER-2 expression by qRT-PCR were compared between ductal and lobular carcinomas and no significant association was observed (median RQ $=1.34 \pm 3.83$ and $\mathrm{RQ}=1.7 \pm 1.02$, respectively; $P=$ 0.7375 , data not shown).

\section{Discussion}

HER-2 gene has been extensively studied as a prognostic and predictive marker in clinical breast cancer, making this receptor a valuable target for the treatment of human breast cancer [22]. HER-2 status is predominantly evaluated by IHC staining, because it is easy to perform and presents a relatively low cost. However, a wide range of sensitivity and specificity was observed among various commercially available antibodies [23]. In addition, FISH is used for those cases that are scored as $2+$. The advantage of FISH testing is that the quantitative interpretation of results with experience is relatively straightforward and concordance rates among observers are higher than with IHC in some studies [for review, [19]]. CISH is an alternative method to evaluate amplifications that requires a conventional light microscopy, permits a more rapid interpretation time and a review of the morphological details. A further advantage of CISH is that the probe signals are permanent and the slides can therefore be archived for long periods of time [24]. Data do not clearly demonstrate the superiority of either IHC or in situ hybridization (ISH) as a predictor of beneficial effects from anti-HER-2 therapy after validated testing has been 

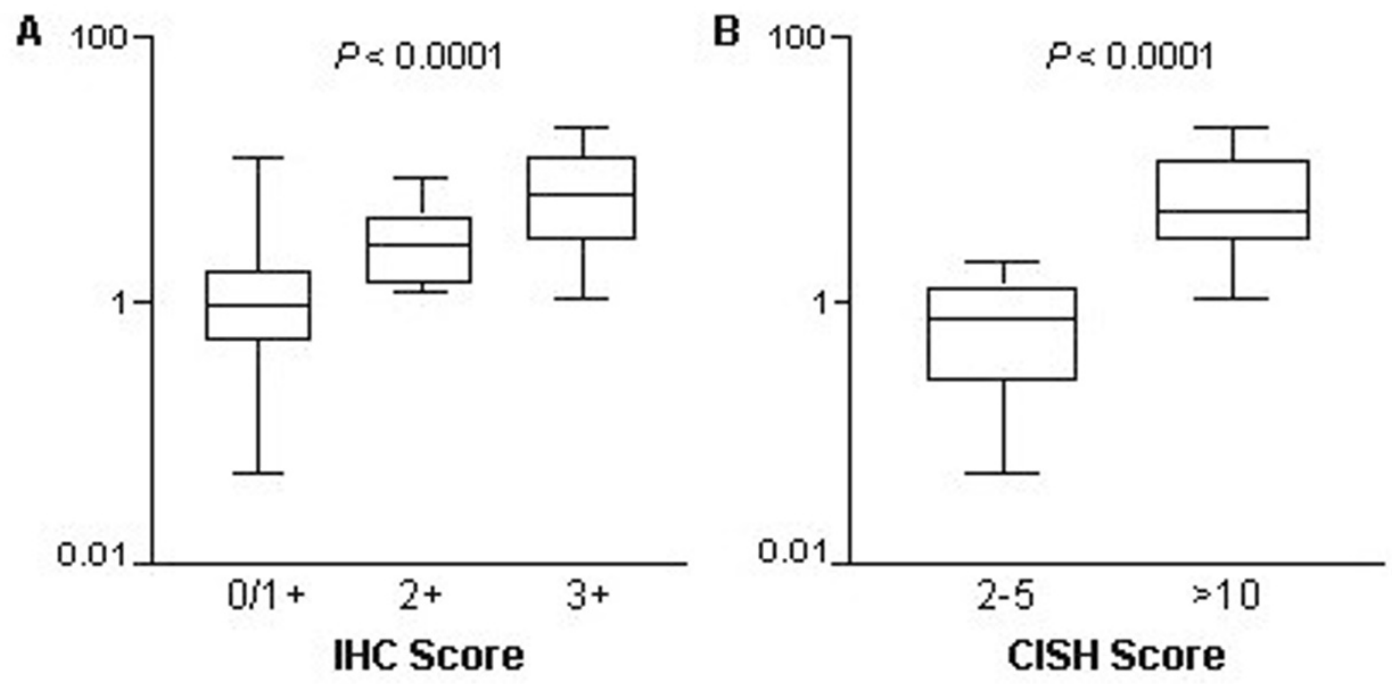

C

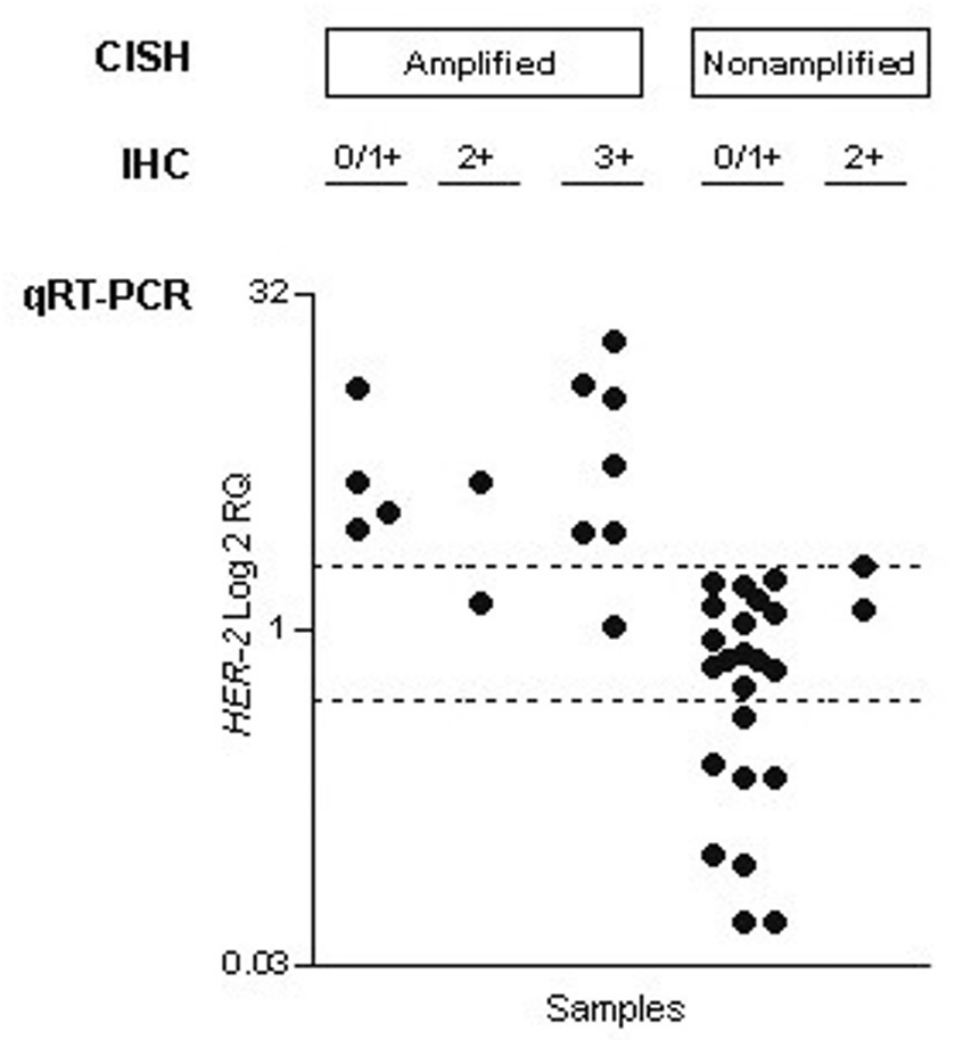

Figure 3

(A) Association between transcript and protein $(1+, 2+$, and $3+)$ expression levels; (B) Correlation between transcript expression level and amplification (2-5 copies and >10 copies or large clusters); (C) CISH, IHC and qRT-PCR results in 37 samples of breast cancer. The samples are indicated in dark circles. The transcript expression values by QRT-PCR are indicated in a log scale. Bars indicate the median value. $P$ values are shown. 


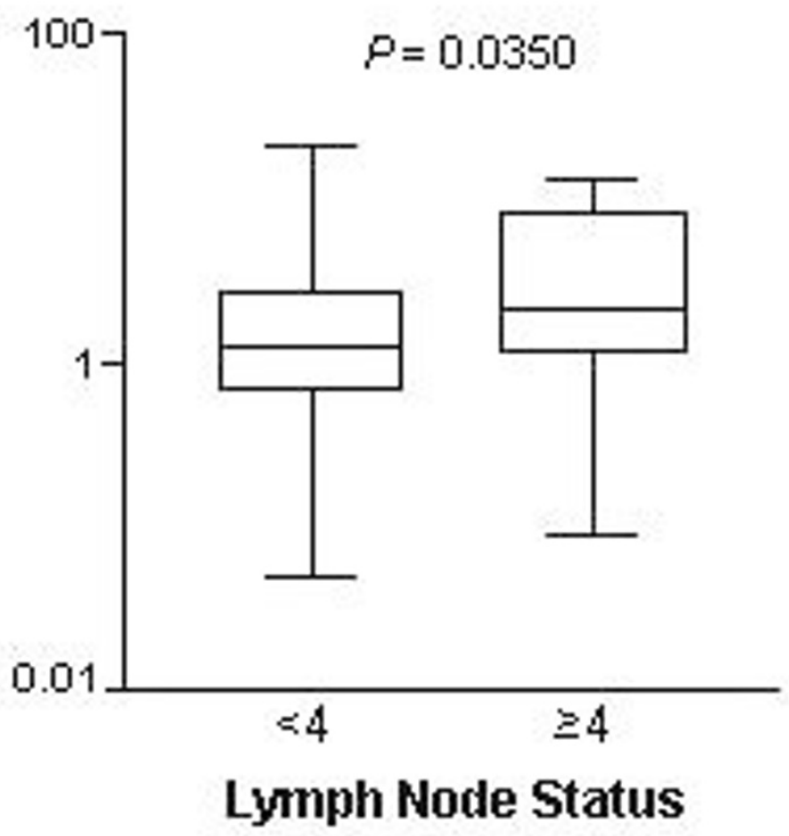

\section{Figure 4 \\ Comparison between HER-2 transcript expression and lymph node involvement ( $<4$ nodes and $\geq 4$ nodes). Bars indicate the median value. $P$ value is shown.}

carefully performed [25]. Quantitative real time PCR has the potential to become standard in terms of its performance, accuracy, sensitivity, broad dynamic range and high throughput capacity $[26,27]$.

Concordance between FISH and CISH was 100\% for the eight cases analyzed. This high concordance was also found by several other studies $[11,14,28]$. One of the eight cases displayed a small frequency of cells showing chromosome 17 polysomy by FISH and showed a score $2+$ by IHC. Peiró et al. [29] showed that all of the polyploidy tumors analyzed presented $2+$ immunostaining. Although a limited number of cases were evaluated by FISH in the present study, the data are in agreement with other studies which indicate that the chromogenic ISH technique seems to be sensitive and specific for the detection of HER-2 amplification in human archival tumor samples [14,28].

CISH analysis revealed intratumoral heterogeneity in three cases. In case A, 50\% of cells showed high-level amplification and nonamplified cells. In addition, this case showed discordant data between IHC and qRT-PCR methodologies, probably due to qRT-PCR false-positive results. The major question is whether cells showing different levels of amplification make any difference or whether a threshold (or its value) percentage of amplified tumor cells is required to define nonamplified and amplified tumors. Regardless of the CISH results, these three patients were treated with tamoxifen and radiotherapy (patients A and B) and radiotherapy and CMF (patient C), according to the IHC results. The outcome was favorable for more than 45 months. Further studies should be performed to clarify the tumoral heterogeneity involving HER-2 amplifications in breast cancer. These three cases were evaluated by FISH and similar results were observed between CISH and FISH analysis for all the cases. When using FISH, it was not possible to determine the two areas observed by CISH, probably due to the restricted number of cells evaluated. Case A presented a higher frequency of amplified cells by CISH in its area 2 than that observed by FISH. Specifically in this case, the paraffin sections used for CISH and FISH methods were not successive and, most likely, different patterns of tumor heterogeneity were evaluated by both methodologies.

Comparison between CISH and IHC results revealed six discordant cases (16\%). These same cases showed concordance when comparing CISH and qRT-PCR data. Many studies have shown high concordance between IHC and $\mathrm{CISH}$; frequently, the discordant cases were 2+ immunostained $[27,30-32]$. In the present study, all of the samples scored as $3+$ by IHC presented HER-2 amplification by CISH. In fact, $>90 \%$ of HER-2 IHC $3+$ tumors present HER-2 gene amplification [19,33]. The concordance between both methodologies was similar to that observed in other studies, varying from $85 \%$ to $95.3 \%$ [24,27,34]. Differences exist in tissue screening between these two techniques. While the IHC test requires that a minimum of $10 \%$ of tumor cells are reactive to be considered positive, CISH scoring requires that more than $50 \%$ of tumor cells show an increase in gene copies to be considered amplified; according the criteria used in the present study. It is conceivable that this difference could account for some of the discordant results observed between IHC and CISH. In the present study, eight cases presenting $2+$ and $3+$ immunostaining showed HER-2 amplification by FISH. The two cases detected as $2+$ by IHC and amplified by FISH also presented high-level amplification using CISH. Cases scored as 2+ and amplified by FISH were also observed in other studies $[10,35,36]$.

A significant correlation was detected between gene and protein expression levels. These data are in agreement with several reports that showed good correlation between transcript and protein data [37-40]. However, ten samples scored as 0 or $1+$ by IHC showed HER-2 overexpression by qRT-PCR. The transcript quantitative analysis revealed two classes of HER-2 overexpression: five cases showed a median $\mathrm{RQ}=4.09 \pm 4.33$ and four of these showed gene amplification by $\mathrm{CISH}$; and five other cases 
presented a median $R Q=2.19 \pm 0.21$, a value very close to the cut-off value selected (2.00). Tse et al. [39] used a cutoff of $\mathrm{RQ}>2.2$ as positive for HER-2 overexpression by qRT-PCR when it was compared to Elisa, IHC, and FISH on sections obtained from paraffin-embedded breast carcinomas.

Currently, the most widely used assay to evaluate gene status in cases scored as $2+$ immunostaining is FISH. However, qRT-PCR has emerged as a potential alternative technique for assessing HER-2 status. The present results demonstrated that $58.3 \%$ of the samples presenting a score of $2+$ overexpressed the transcript. Among the current samples, four out of five patients that presented discordant results $(2+$ immunostaining and $\mathrm{RQ} \leq 2.00)$ showed a favorable outcome, indicating that HER-2 status by qRT-PCR could be performed on $2+$ staining tumors with potential value regarding the management of these patients. Of the patients presenting $2+$ staining and $\mathrm{RQ}>2.00$ (eight cases), three presented metastasis, one revealing spreading to the bone and two to the lung.

A higher concordance rate was observed between $3+$ score by IHC and overexpression by qRT-PCR. Only one sample that presented 3+ status and HER-2 amplification showed transcript downexpression. This case, showing a qRT-PCR false-negative result, probably resulted from the dilution of cells carrying amplified genes among nontumor cells [41], although the sample was submitted to microdissection.

Concordance between the IHC and qRT-PCR results was $78.9 \%$. The discordance between these methodologies could include differences in the specimen used in the experiments (paraffin-embedded and fresh tumor tissue, respectively). Two other possible causes for discrepancy exist: intraobserver error, due to subjectivity of the IHC interpretation; and qRT-PCR analysis, which can cause discrepancies particularly in the initial cycles, which depend not only on the melting temperature of the amplicon, but also on the behavior of the genomic vicinity of the amplicon [42,43]. Using PCR-based methods, the expression of tumor- or tissue-specific genes and the presence of genetic abnormalities can be detected in a clinical specimen with higher sensitivity (one malignant cell out of $10^{6}-10^{7}$ normal cells) than that of other techniques such as light microscopy (one malignant cell out of $10^{2}-$ $10^{3}$ normal cells). Using RT-PCR the nucleic acid molecules can be amplified $10^{10}$-fold [for review, [44]]. Moreover, HER-2 overexpression can be detected in 0.1 cell equivalent spiked into $8 \mathrm{~mL}$ of peripheral blood using qRT-PCR and the detection limited increases to 10 and 50 cell equivalent per $8 \mathrm{~mL}$ in cell lines expressing intermediate and low levels of HER-2 [45].
Comparison between qRT-PCR data and CISH results showed that the gene expression median was correlated with gene copy number, a finding also observed by Bergqvist et al. [46]. HER-2 gene amplification is the most prevalent genetic mechanism driving HER-2 overexpression. The discordant cases $(8.1 \%)$ showed $2+$ and $3+$ immunostaining, confirming the CISH results. In this study, the concordance between qRT-PCR and FISH was $100 \%$. High concordances were observed by other studies $[23,47]$.

In the present study, a high correlation rate among the three procedures used to score HER-2 status in breast carcinomas was observed. The correlation between CISH and qRT-PCR was higher than CISH and IHC, which was higher than qRT-PCR and IHC for the samples evaluated by all these procedures. In fact, CISH and qRT-PCR are complementary methodologies for evaluating HER-2 status.

No correlation was found between HER-2 expression by IHC or gene copy number and clinicopathological data. However, a significant association was observed between lymph node status and HER-2 transcript expression by qRT-PCR. Peiró et al. [48] analyzed HER-2 status by IHC and CISH and observed a correlation with histological grade and lymph-vascular invasion, but no association was found with age, tumor size and Ki-67 status. Similarly, the absence of correlation between HER-2 status and clinical and pathological features has been reported in other studies $[32,43]$.

No statistically significant difference was observed between ductal and lobular carcinomas evaluated by qRTPCR. Among the lobular carcinomas, amplification by CISH was observed in one case, followed by HER-2 overexpression and negative IHC staining. In a previous study, this case was confirmed as negative for e-cadherin protein expression and presented $C D H 1$ promoter hypermethylation [49]. Li-Ning-T et al. [35] evaluated five invasive lobular tumors and none showed amplification by $\mathrm{CISH}$, however two cases presented $2+$ immunostaining.

\section{Conclusion}

In conclusion, the present results suggest that HER-2 status can be performed by CISH and qRT-PCR analysis. CISH combines the advantages of IHC and FISH and is a promising practical alternative to FISH, while qRT-PCR is reliable, semiautomated and fast; and both methodologies can be performed in most pathology laboratories. However, there are several limitations to apply qRT-PCR as a routine method for clinical application, including the use of fresh frozen tissue, microdissection procedures and the incapacity to address cell-to-cell variations. In addi- 
tion, the data confirm that HER-2 overexpression is associated with a worst prognostic in human breast tumors.

\section{Competing interests}

The authors declare that they have no competing interests.

\section{Authors' contributions}

FER participated in the study design, in defining the casuistic used, carried out the qRT-PCR analysis and helped to draft the manuscript. SMS, CGTS, and NAB performed the CISH analysis. FAMN, MACD, and FAS carried out the pathological and immunohistochemistry analysis. JRFC provided the samples and follow-up data. SRR conceived the study, participated in its design, performed the statistical analysis and helped to draft the manuscript. All authors read and approved the final manuscript.

\section{Acknowledgements}

The authors would like to thank Dr. Francisco Carlos Quevedo and Adalberto Campanha, Amaral Carvalho Hospital, Jau, SP, for their assistance with the immunohistochemical analysis; Dr. Fausto Viterbo for providing the normal breast samples for quantitative real time PCR analysis; Flávia Cilene Maciel da Cruz Alves for her assistance with the $\mathrm{CISH}$ technique; José Ivanildo Neves for his technical assistance in the FISH assays; and for Invitrogen, Sao Paulo, Brazil for supplying the Zymed SPoT-Light HER2 CISH Kit. This study was supported by grants from the Conselho Nacional de Pesquisa (CNPq) and Fundação de Amparo à Pesquisa do Estado de São Paulo (FAPESP), Brazil.

\section{References}

I. Coussens L: Tyrosine kinase receptor with extensive homology to EGF receptor shares chromosomal location with neu oncogene. Science 1985, 230:1132-1/39.

2. King CR, Kraus MH, Aaronson AS: Amplification of a novel verbB-related gene in a human mammary carcinoma. Science 1985, 229:974-976.

3. Slamon DJ, Clark GM, Wong SG, Levin WJ, Ullrich A, McGuire WL: Human breast cancer: correlation of relapse and survival with amplification of the HER-2/neu oncogene. Science 1987, 235: $177-182$.

4. Slamon DJ, Godolphin W, Jones LA, Holt JA, Wong SG, Keith DE, Levin WJ, Stuart SG, Udove J, Ullrich A, Press MF: Studies of the HER-2/neu proto-oncogene in human breast and ovarian cancer. Science 1989, 244:707-7|2.

5. Ross JS, Fletcher JA: HER-2/neu (c-erb-B2) gene and protein in breast cancer. Clin Pathol I999, I I 2(Suppl I):S53-67.

6. Carlomagno C, Perrone F, Gallo C, De Laurentiis M, Lauria R, Morabito A, Pettinato G, Panico L, D'Antonio A, Bianco AR, De Placido S: c-erb B2 overexpression decreases the benefit of adjuvant tamoxifen in early-stage breast cancer without axillary lymph node metastases. J Clin Oncol 1996, 14:2702-2708.

7. Tetu B, Brisson J, Plante V, Bernard P: p53 and c-erbB-2 as markers of resistance to adjuvant chemotherapy in breast cancer. Mod Pathol 1998, II:823-830.

8. Cobleigh MA, Vogel CL, Tripathy D, Robert NJ, Scholl S, Fehrenbacher L, Wolter JM, Paton V, Shak S, Lieberman G, Slamon DJ: Multinational study of the efficacy and safety of humanized antiHER2 monoclonal antibody in women who have HER2-overexpressing metastatic breast cancer that has progressed after chemotherapy for metastatic disease. J Clin Oncol I999, I 7:2639-2648.

9. Keefe DL: Trastuzumab-associated cardiotoxicity. Cancer 2002, 95:1592-1600.

10. Tanner M, Gancberg D, Di Leo A: Chromogenic in situ hybridization: a practical alternative for fluorescence in situ hybridization to detect HER-2/neu oncogene amplification in archival breast cancer samples. Am \& Pathol 2000, 157:1467-1472

II. Zhao J, Wu R, Au A, Marquez A, Yu Y, Shi Z: Determination of HER2 gene amplification by chromogenic in situ hybridization (CISH) in archival breast carcinoma. Mod Pathol 2002, 15:657-665.

12. Arnould L, Denoux Y, MacGrogan G, Penault-Llorca F, Fiche M, Treilleux I, Mathieu MC, Vincent-Salomon A, Vilain MO, Couturier J: Agreement between chromogenic in situ hybridisation (CISH) and FISH in the determination of HER2 status in breast cancer. Br J Cancer 2003, 88: I587-I59I.

13. Lambros MBK, Natrajan R, Reis-Filho JS: Chromogenic and fluorescent in situ hybridization in breast cancer. Hum Pathol 2007, 38: I 105-II 22.

14. Hauser-Kronberger C, Dandachi N: Comparison of chromogenic in situ hybridization with other methodologies for HER2 status assessment in breast cancer. J Mol Histol 2004, 35:647-653.

15. Bustin SA, Nolan T: Pitfalls of Quantitative Real- Time Reverse-Transcription Polymerase Chain Reaction. J Biomol Tech 2004, 15:155-166.

16. WHO World Health Organization: International Classification of Diseases for Oncology. 2nd edition. World Health Organization, Geneva; 1990.

17. UICC União Internacional Contra ○ Câncer: Classificação dos tumores malignos. 5th edition. Ministério da Saúde, Rio de Janeiro-Brasil; 1998.

18. Bloom MJC, Richardson WW: Histologic grading and prognosis in breast cancer: a study of 1709 cases. Br J Cancer 1957, I I:358-377.

19. Hicks DG, Tubbs RR: Assessment of the HER2 status in breast cancer by fluorescence in situ hybridization: a technical review with interpretive guidelines. Hum Pathol 2005, 36:250-261.

20. Rosa FE, Caldeira JRF, Felipes J, Bertonha FB, Quevedo FC, Domingues MAC, Moraes Neto FA, Rogatto SR: Evaluation of estrogen receptor alpha and beta and progesterone receptor expression and correlation with clinicopathological factors and proliferative marker Ki-67 in breast cancers. Hum Pathol 2008, 39:720-730.

21. Livak KJ, Schmittgen TD: Analysis of relative gene expression data using real-time quantitativePCR and the $2^{\text {-ddct }}$ method. Methods 200I, 25:402-408.

22. Ferretti G, Felici A, Papaldo P, Fabi A, Cognetti F: HER2/neu role in breast cancer: from a prognostic foe to a predictive friend. Curr Opin Obstet Gynecol 2007, 19:56-62.

23. Bempt I Vanden, Vanhentenrijk $\mathrm{V}$, Drijkoningen M, Wlodarska I, Vandenberghe P, De Wolf-Peeters C: Real-time reverse transcription-PCR and fluorescence in-situ hybridization are complementary to understand the mechanisms involved in HER-2/neu overexpression in human breast carcinomas. Histopathology 2005, 46:43I-44I.

24. Kim GY, Oh YL: Chromogenic in situ hybridization analysis of HER-2/neu status in cytological samples of breast carcinoma. Cytopathology 2004, 15:315-320.

25. Wolff AC, Hammond ME, Schwartz JN, Hagerty KL, Allred DC, Cote RJ, Dowsett M, Fitzgibbons PL, Hanna WM, Langer A, McShane LM, Paik S, Pegram MD, Perez EA, Press MF, Rhodes A, Sturgeon C, Taube SE, Tubbs R, Vance GH, Vijver M van de, Wheeler TM, Hayes DF, American Society of Clinical Oncology, College of American Pathologists: American Society of Clinical Oncology/College of American Pathologists guideline recommendations for human epidermal growth factor receptor 2 testing in breast cancer. J Clin Oncol 2007, 25: I I 8- I 45.

26. Bièche I, Parfait B, Laurendeau I, Girault I, Vidaud M, Lidereau R: Quantification of estrogen receptor alpha and beta expression in sporadic breast cancer. Oncogene 200I, 20:8I09-8II 5 .

27. Ntoulia M, Kaklamanis L, Valavanis C, Kafousi M, Stathopoulos E, Arapantoni P, Mavroudis D, Georgoulias V, Lianidou ES: HER-2 DNA quantification of paraffin-embedded breast carcinomas with LightCycler real-time PCR in comparison to immunohistochemistry and chromogenic in situ hybridization. Clin Biochem 2006, 39:942-946.

28. Pothos A, Plastira K, Plastiras A, Vlachodimitropoulos D, Goutas N, Angelopoulou R: Comparison of chromogenic in situ hybridisation with fluorescence in situ hybridisation and immunohistochemistry for the assessment of Her-2/neu oncogene in 
archival material of breast carcinoma. Acta Histochem Cytochem 2008, $41: 59-64$.

29. Peiró G, Aranda FI, Adrover E, Niveiro M, Alenda C, Payá A, Seguí J: Analysis of HER2 by chromogenic in situ hybridization and immunohistochemistry in lymph node-negative breast carcinoma: prognostic relevance. Hum Pathol 2007, 38:26-34.

30. Kumamoto H, Sasano H, Taniguchi T, Suzuki T, Moriya T, Ichinohasama R: Chromogenic in situ hybridization analysis of HER2/neu status in breast carcinoma: application in screening of patients for trastuzumab (Herceptin) therapy. Pathol Int 200I, 5 I:579-584.

31. Dandachi N, Dietze O, Hauser-Kronberger C: Chromogenic in situ hybridization: a novel approach to a practical and sensitive method for the detection of HER2 oncogene in archival human breast carcinoma. Lab Invest 2002, 82:1007-I0I4.

32. Madrid MA, Lo RW: Chromogenic in situ hybridization (CISH): a novel alternative in screening archival breast cancer tissue samples for HER-2/neu status. Breast Cancer Res 2004, 6:R593-600.

33. Ma Y, Lespagnard L, Durbecq V, Paesmans M, Desmedt C, GomezGaldon M, Veys I, Cardoso F, Sotiriou C, Di Leo A, Piccart MJ, Larsimont $D$ : Polysomy 17 in HER-2/neu status elaboration in breast cancer: effect on daily practice. Clin Cancer Res 2005, I I:4393-4399.

34. Di Palma S, Collins N, Faulkes C, Ping B, Ferns G, Haagsma B, Layer G, Kissin MW, Cook MG: Chromogenic in situ hybridisation (CISH) should be an accepted method in the routine diagnostic evaluation of HER2 status in breast cancer. J Clin Pathol 2007, 60:1067-1068.

35. Li-Ning TE, Ronchetti R, Torres-Cabala C, Merino MJ: Role of chromogenic in situ hybridization (CISH) in the evaluation of HER2 status in breast carcinoma: comparison with immunohistochemistry and FISH. Int J Surg Pathol 2005, 13:343-35 I.

36. Vocaturo A, Novelli F, Benevolo M, Piperno G, Marandino F, Cianciulli AM, Merola R, Donnorso RP, Sperduti I, Buglioni S, Mottolese M: Chromogenic In Situ Hybridization to detect HER-2/neu gene amplification in histological and ThinPrep ${ }^{\circledR}$-processed breast cancer fine-needle aspirates: a sensitive and practical method in the Trastuzumab era. The Oncologist 2006 I I:878-886

37. Schlemmer BO, Sorensen BS, Overgaard J, Olsen KE, Gjerdrum LM, Nexo E: Quantitative PCR - new diagnostic tool for quantifying specific mRNA and DNA molecules: HER2/neu DNA quantification with LightCycler real-time PCR in comparison with immunohistochemistry and fluorescence in situ hybridization. Scand J Clin Lab Invest 2004, 64:5 I I-522.

38. Bossard C, Bieche I, Le Doussal V, Lidereau R, Sabourin JC: Realtime RT-PCR: a complementary method to detect HER-2 status in breast carcinoma. Anticancer Res 2005, 25:4679-4683.

39. Tse C, Brault D, Gligorov J, Antoine M, Neumann R, Lotz JP, Capeau $\mathrm{J}$ : Evaluation of the quantitative analytical methods real-time PCR for HER-2 gene quantification and ELISA of serum HER-2 protein and comparison with fluorescence in situ hybridization and immunohistochemistry for determining HER-2 status in breast cancer patients. Clin Chem 2005, 5I:1093-1101.

40. Vinatzer U, Dampier B, Streubel B, Pacher M, Seewald MJ, Stratowa $C$, Kaserer K, Schreiber M: Expression of HER2 and the coamplified genes GRB7 and MLN64 in human breast cancer: quantitative real-time reverse transcription-PCR as a diagnostic alternative to immunohistochemistry and fluorescence in situ hybridization. Clin Cancer Res 2005, I I:8348-8357.

41. Lehmann U, Glockner S, Kleeberger W, von Wasielewski HF, Kreipe $\mathrm{H}$ : Detection of gene amplification in archival breast cancer specimens by laser-assisted microdissection and quantitative real-time polymerase chain reaction. Am J Pathol 2000, I56: I855-1864.

42. Wilhelm J, Hahn M, Pingoud A: Influence of DNA target melting behavior on real-time PCR quantification. Clin Chem 2000, 46: I738-I743

43. Kim YR, Choi JR, Song KS, Chong WH, Lee HD: Evaluation of HER2/neu status by real-time quantitative PCR in breast cancer. Yonsei Med J 2002, 43:335-340.

44. Mocellin S, Keilholz U, Rossi CR, Nitti D: Circulating tumor cells: the 'leukemic phase' of solid cancers. Trends Mol Med 2006, 12:130-139.
45. You F, Roberts LA, Kang SP, Nunes RA, Dias C, Iglehart JD, Solomon NA, Friedman PN, Harris LN: Low-level expression of HER2 and CK19 in normal peripheral blood mononuclear cells: relevance for detection of circulating tumor cells. J Hematol Oncol 2008, I:2.

46. Bergqvist J, Ohd JF, Smeds J, Klaar S, Isola J, Nordgren H, Elmberger GP, Hellborg H, Bjohle J, Borg AL, Skoog L, Bergh J: Quantitative real-time PCR analysis and microarray-based RNA expression of HER2 in relation to outcome. Ann Oncol 2007, I 8:845-850

47. Kostopoulou E, Vageli D, Kaisaridou D, Nakou M, Netsika M, Vladica N, Daponte A, Koukoulis G: Comparative evaluation of noninformative HER-2 immunoreactions (2+) in breast carcinomas with FISH, CISH and QRT-PCR. Breast 2007, 16:6I5-624.

48. Peiró G, Aranda FI, Adrover E, Niveiro M, Alenda C, Payá A, Seguí J: Analysis of HER2 by chromogenic in situ hybridization and immunohistochemistry in lymph node-negative breast carcinoma: prognostic relevance. Hum Pathol 2007, 38:26-34.

49. Caldeira JR, Prando EC, Quevedo FC, Neto FA, Rainho CA, Rogatto SR: CDHI promoter hypermethylation and E-cadherin protein expression in infiltrating breast cancer. BMC Cancer 2006 , 6:48.

\section{Pre-publication history}

The pre-publication history for this paper can be accessed here:

http://www.biomedcentral.com/1471-2407/9/90/prepub
Publish with Bio Med Central and every scientist can read your work free of charge

"BioMed Central will be the most significant development for disseminating the results of biomedical research in our lifetime. "

Sir Paul Nurse, Cancer Research UK

Your research papers will be:

- available free of charge to the entire biomedical community

- peer reviewed and published immediately upon acceptance

- cited in PubMed and archived on PubMed Central

- yours - you keep the copyright 